Jurnal Sastra Indonesia

\title{
Absurditas Naskah Drama "Pelajaran" karya Eugene Ionesco
}

\author{
Eka Yusriansyah ${ }^{\bowtie}$
}

Fakultas Ilmu Budaya, Universitas Mulawarman, Samarinda, Indonesia

\begin{tabular}{l} 
Info Artikel \\
\hline Sejarah Artikel: \\
Diterima Desember 2018 \\
Disetujui Mei 2019 \\
Dipublikasikan Juli 2019
\end{tabular}

Kata kunci:

absurditas,

eksistensialisme, naskah

drama, Eugene Ionesco.

Keywords:

absurdity, existentialism,

drama script, Eugene

Ionesco.

\begin{abstract}
Abstrak
Penelitian ini bertujuan untuk menelusuri wacana absurditas yang terlukis dalam naskah drama "Pelajaran" karya Eugene Ionesco. "Pelajaran" tergolong naskah absurd yang berarti berada di luar konvensi drama pada umumnya, tidak beralur, bertemakan nihilisme dan kesenduan metafisik, serta disesaki dialog yang hanya berupa celotehan tidak nyambung. Kepekaan intelektual dan penghayatan eksistensi kehidupan menjadi syarat kompetensi interpretasi. Penelitian ini adalah penelitian deskriptif kualitatif yang memanfaatkan metode hermeneutika dengan mengadopsi pembacaan heuristik dan hermenuitik. Teori semiotika Riffaterre dan teori drama absurd digunakan untuk mengungkapkan tanda-tanda sebagai pembangun absurditas di luar logika. Hasil penelitian menunjukkan bahwa "Pelajaran" menyuguhkan absurditas kehidupan metafisik, kesia-siaan, pemberontakan, dan kematian yang dikemas melalui absurditas alur, penokohan, dan dialog irrasional.
\end{abstract}

\begin{abstract}
This research aims to investigate absurdity in "Pelajaran" drama script written by Eugene Ionesco. "Pelajaran" belongs to the kind of absurd drama script since it breaks structure convention of common drama script. It is such unconventional kind of drama script which has no plot, unclear characterization, nihilism topics such metaphysical things, being isolate, rebellion, and death, also has irrational dialogue which only tells about unimportant things. This research belongs to descriptive qualitative research which used hermeneutic methods contained of two reading methods such heuristic and hermeneutic. The theory of semiotic Riffaterre applied in analyzing the symbols constructed in the text which combined with the theory of drama absurd suggested by Martin Esslin used to find out the absurdity in the text. The result of the research shows that "Pelajaran" presents the absurdity of life such metaphysics, disconsolate, rebellion, and death. Those all things presented through absurdity of plot, characterization, and irrational dialogue.
\end{abstract}

$\begin{array}{ll}{ }^{凶} \text { Alamat korespondensi: } & \text { P-ISSN 2252-6315 } \\ \text { Jalan Pulau Flores No 1 Samarinda 75112 } & \text { E-ISSN 2685-9599 } \\ \text { E-mail: ekayusriansyah@fib.unmul.ac.id } & \end{array}$




\section{PENDAHULUAN}

Absurd, di dalam istilah sastra adalah tidak masuk akal, mustahil. Yang dimaksud dengan karya sastra absurd adalah karya sastra (drama atau cerkan) yang berlandaskan anggapan bahwa pada dasarnya kondisi manusia itu absurd, dan bahwa kondisi ini secara tepat hanya dapat dilukiskan dalam karya yang absurd (Sudjiman, 1986: 1). Sementara Ionesco dalam Esslin (2008: 4) menyatakan bahwa absurd adalah tanpa tujuan, terenggut dari akal religi, metafisik, dan transendental, manusia menjadi kehilangan segala tindakannya tidak masuk akal, absurd, dan sia-sia. Konsep absurd dalam karya sastra khususnya naskah drama dapat dicermati dengan cara membandingkannya dengan naskah drama/teater konvensional karena kelahiran drama absurd adalah reaksi dari drama konvensional. Drama absurd disebut juga sebagai drama inkonvensional, artinya drama yang tidak sesuai lagi dengan konvensi-konvensi yang ada dalam drama konvensional seperti alur yang kadang irrasional, penokohan yang tidak logis, tokoh yang sering kali berubah karakter, dan peristiwa-peristiwa yang di luar pengalaman rasional.

Absurdisme merupakan salah satu mazhab sastra yang berkembang pasca Perang Dunia II yang dalam perkembangannya tidak dapat dipisahkan dengan mazhab eksistensialisme. Kierkegaard, Heidegger, Jaspers, dan Sartre. Kierkegaard (1813-1855) adalah peletak dasar eksistensialisme. Para eksponen tersebut lebih dikenal sebagai seorang filsuf daripada sastrawan (Hasan, 1976). Perlu menyebut seorang nama lagi yaitu Albert Camus, karena Camuslah yang menghubungkan mata rantai absurdisme dengan eksistensialisme. Bertolak dari cerita Mite Sisifus yang diambil dari mitologi Yunani, benih-benih absurdisme tampak tumbuh subur di dalam karya sastra, baik prosa maupun drama hingga pertunjukan teater. Hal inilah yang menimbulkan munculnya banyak sastrawan yang beraliran absurd, antara lain, Becket, Ionesco, dan Adamov.

Dalam makalah ini akan dibahas salah satu karya dari Eugene Ionesco seorang dramawan Perancis berkebangsaan Rumania. Karyanya berupa suatu karangan prosa atau puisi yang memotret kehidupan atau tokoh dengan bantuan dialog dan pantomim atau gerak yang direncanakan untuk sebuah pertunjukan atau pementasan teater di atas panggung, sebuah lakon (Karmini, 2011: 142).

Artikel ini memandang naskah "Pelajaran" sebagai bentuk komunikasi antara pengarang dan pembaca yang memanfaatkan bahasa sebagai media utama. Bahasa yang dimanfaatkan adalah bahasa dengan sistem pemaknaan tataran kedua yang dibangun di atas bahasa sebagai sistem pemaknaan tataran pertama atau sistem primer. Oleh karenanya di dalam sastra, bahasa bukan sekadar saluran pengkomunikasian informasi, melainkan merupakan alat untuk menggerakkan dan menyusun dunia sendiri. Oleh karenanya "Pelajaran" harus diinterpretasi untuk mendapatkan pesan dan makna yang terkandung di dalamnya.

Wacana merupakan sebuah cara untuk memahami dan membicarakan suatu dunia (Jorgensen dan L. J. Philips, 2007). "Pelajaran" sebagai sebuah wacana, cara pengarang naskah drama "Pelajaran" Eugene Ionesco dalam membicarakan dan memahami absurdisme yang terkandung di dalam dunia miniatur yang menginventarisasikan segala gejala sosial yang dikerangkakan dalam proses kreatif dan imajinatif, dalam hal ini dunia miniatur tersebut adalah dunia "Pelajaran". Di samping itu, "Pelajaran" selaku bentuk komunikasi adalah sebuah komunikasi yang terdiri dari tanda-tanda yang membentuk sebuah makna. Agar tandatanda tersebut dapat diinterpretasi, maka teori semiotiklah yang digunakan guna mengupas makna dari tanda-tanda yang digunakan dalam komunikasi tersebut. Preminger (2001: 89) menjelaskan bahwa semiotika mempelajari sistem, aturan-aturan, dan konvensi-konvensi yang memungkinkan tanda-tanda tersebut mempunyai arti.

Dari waktu ke waktu semiotik digunakan sebagai pendekatan untuk memecahkan masalah praktis disamping mengalami perkembangan secara teortis. Semiotik sebagai contoh, dibidang 
budaya membantu menemukan cara-cara bagaimana karya-karya dalam pelbagai genre seni ditampilkan untuk mencapai efek tertentu.

"Pelajaran" dijadikan objek penelitian oleh Jihan Kusuma Wardhani Wardhani (2013) “Tokoh Profesor dalam Naskah 'Pelajaran' Karya Eugene Ionesco sutradara Jihan Kusuma Wardani (Kajian Simbol dan Pemaknaan)." Penelitian ini membahas penokohan profesor dalam penggarapan naskah "Pelajaran" yang disutradarai oleh Jihan Kusuma Wardani dengan menggunakan metode penyutradaraan Suyatna Anirun dan W.S Rendra. Selain Wardhani, tidak ditemukan lagi tulisan ilmiah yang menelaah "Pelajaran." Selain Wardhani (2013), tidak ditemukan lagi kajian ilmiah terhadap naskah "Pelajaran." Namun, terdapat beberapa penelitian terdahulu yang juga menelaah absurditas naskah drama, antara lain Intan Suri (2012) dan Rais (2017) yang menelaah absurditas dalam naskah drama dengan bertolak dari eksistensialisme Sartre.

Penelitian ini bertujuan untuk menelusuri absurditas yang tersaji dalam "Pelajaran" dengan memanfaatkan teori semiotik sebagai senjata utama dalam mengupas tanda-tanda yang menyembunyikan makna. Kemudian analisis dilanjutkan dengan penerapan teori drama absurd Esslin yang menganggap absurditas sebagai drama murni yang menyajikan cerita abstrak, mimpi, fantasi, tokoh-tokoh yang kerap kali bertingkah konyol dan tidak masuk akal, dan verbal nonsense yaitu permainan kata-kata yang tidak ada artinya (Esslin, 2008: 337-338). Oleh karena itu, masalah yang hendak dipecahkan adalah apa dan bagaimana absurditas diwacanakan dalam naskah drama "Pelajaran" karya Eugene Ionesco.

\section{METODE}

Penelitian ini adalah penelitian kualitatif yang memanfaatkan metode pembacaan dan teknik kartu data dalam pengumpulan data. Data penelitian bersumber dari naskah drama "Pelajaran" karya Eugene Ionesco yang diterjemahkan oleh Toto Sudarto Bachtiar sebagai data primer dan buku-buku literatur yang relevan serta artikel dan jurnal dari internet sebagai data sekunder. Data yang diperoleh kemudian dianalisis dengan metode deskriptifanalitik, yaitu mendeskripsikan fakta-fakta tekstual yang kemudian dianalisis dan diuraikan secara deskriptif dengan pola pikir deduktifinduktif.

Dalam tahap analisis data, data ditelaah menggunakan teori semiotik yang dikemukakan oleh Riffaterre. Riffatere (dalam Pradopo, 1995: 135) menyebutkan bahwa analisis semiotik terhadap karya sastra mencakup dua pembacaan yaitu pembacaan heuristik dan pembacaan hermeneutik. Heuristik adalah pembacaan berdasarkan struktur bahasanya dan hermeneutika adalah pembacaan berdasarkan konvensi sastranya serta menafsirkan makna dan pesan subjektif. Sementara dalam menelaah wacana absurditas diaplikasikan teori absurdisme Martin Esslin yang lahir dari konsep filsafat eksistensialisme, khususnya yang digagas oleh Jean Paul Sartre dan Albert Camus. Data yang telah dianalisis kemudian disajikan dalam bentuk informal secara deskriptif kualitatif, yaitu dalam bentuk kata-kata dan narasi dengan pola pikir deduktif-induktif.

\section{HASIL DAN PEMBAHASAN}

Naskah "Pelajaran" menyajikan tiga tokoh yaitu seorang profesor sebagai tokoh primer atau utama, murid sebagai tokoh sekunder, dan pembantu sebagai tokoh tritagonis. Naskah "Pelajaran" tersebut bercerita tentang seorang profesor yang memanfaatkan peran dominatifnya selaku orang terpelajar dan memperlakukan murid-muridnya semena-mena bahkan sampai membunuhnya ketika mereka tidak sependapat dengan profesor dalam memandang dunia yang absurd ini.

\section{Absurditas sebagai Pendobrak Drama Inkonvensional}

Absurditas tidak dapat dilepaskan dari pemikiran filsafat eksistensialisme yang memandang segala gejala dengan berpangkal pada eksistensi yang berarti keberadaan. Lebih 
khusus lagi, eksistensialisme mempertanyakan hakikat kehidupan dengan menempatk an manusia sebagai pusatnya, sehingga menghasilk an pertentangan tragis antara manusia dengan dunianya. Eksistensialisme percaya bahwa alam semesta tidak mempunyai aturan dan nilai-nilai yang tetap sehingga setiap orang harus menciptakan aturan dan nilai-nilainya masingmasing. Eksistensialisme juga mempertanyakan tentang keberadaan hidup manusia dan cenderung pada jawaban yang bernada pesimis, bahwa hidup sangat tidak rasional.

Naskah absurd melahirkan daya ungkap baru, orisinil, inovatif serta filosofis dengan berbagai wacana yang mengesankan, yang pada gilirannya dapat mengubah berbagai persepsi, perasaan, sikap, dan strategi berpikir dalam kaitanyya dengan partitur kehidupan. Menurut Esslin, drama absurd tidak mengetengahkan intelektualitas dan spiritualitas yang bertendensi untuk menilai persoalan benar dan salah dan gagasan-gagasan moralitas. Naskah absurd seringkali dianggap sebagai naskah omong kosong atau mistifikasi yang sukar dipahami dan memiliki makna tertentu. Naskah absurd dinilai sebagai naskah sukar, kasar, bahkan kurang ajar karena bertolak belakang dengan kriteria dan standar konvensi pada umumnya. Jika naskah pada umumnya dibangun oleh alur cerita yang cerdas, dialog yang terarah, penokohan yang halus, dan tema yang jelas maka di dalam naskah absurd semuanya tidak diketemukan karena naskah absurd tidak beralur dan kerap kali tanpa awal atau akhir dan dialognya pun sering hanya berupa ocehan yang tidak ada juntrungnya (Esslin, 2008: 3).

Naskah absurd mulanya bertolak dari absurditas kehidupan, memaknai kesenduan metafisis dan ketidakbermaknaannya hidup sebagai tema dramawan terdahulu, seperti halnya naskah-naskah Sartre dan Camus, yang tentunya mengekspresikan muatan filosofis secara rasionalistik, elegan, dan gaya diskursif moralis sehingga masih mencerminkan konvensi lama. Bertolak belakang dengan dramawan eksistensialis tersebut, dramawan absurd tidak lagi menyoalkan absurditas manusia, namun hanya menyajikan keadaannnya (Esslin, 2008:
5). Selanjutnya, naskah absurd bertendensi untuk mengarah pada devaluasi radikal bahasa, artinya mengarah pada penyimpangan bahasa sebagai penghambat komunikasi.

\section{Absurditas dalam "Pelajaran"}

Pada umumnya drama diawali dengan prolog, pembagian atas babak cerita, dan epilog. Drama disajikan dengan menyebutkan para pelaku dan para pemeran lain pada awal dialog dan cerita. Tidak ada naskah drama yang ditulis semata-mata untuk dibaca saja. Oleh karena itu, pada umumnya pada awal cerita naskah drama disajikan gambaran cerita awal yang dapat menentukan seting, properti, dan perlengkapan yang dibutuhkan dalam pementasan.

Di dalam naskah "Pelajaran" tidak terdapat prolog yang menggambarkan awal cerita dan setting serta perlengkapan lainnya yang dibutuhkan dalam persiapan sebelum pentas. Ini merupakan salah satu ciri khas Ionesco dalam menulis naskah drama. Judul naskah drama tersebut sudah merupakan tanda, "Pelajaran", seperti yang kita ketahui adalah sebuah ilmu pengetahuan. Dapat diinterpretasikan bahwa kata "Pelajaran" tersebut merupakan sebuah falsafah atau ajaran dan pedoman dalam menjalani kehidupan. Naskah drama "Pelajaran" mengajarkan sebuah falsafah dan ajaran hidup demi mewujudkan kehidupan yang lebih bertanggung jawab.

Tokoh profesor juga mengandung tanda dan simbol, dimana profesor merupakan simbol dari seseorang yang terpelajar atau seorang ahli dalam bidang ilmu pengetahuan. Dapat diinterpretasikan bahwa profesor merupakan sebuah simbol dari seseorang yang berbudi luhur dengan falsafah kehidupan yang luhur. Akan tetapi tokoh profesor di dalam naskah tersebut kehilangan sebuah eksistensi sebagai seseorang yang berbudi luhur dan yang seharusnya menjadi suri tauladan bagi murid atau pengikutnya. Malahan suri tauladan tersebut kehilangan eksistensi atau keberadaannya sebagai sosok publik figur dengan melakukan tindak kriminal yaitu pembunuhan terhadap muridnya sendiri. Di dalam naskah "Pelajaran"tersebut, tokoh 
profesor memanfaatkan eksistensinya sebagai sosok terpelajar dengan menganiaya muridnya. Dalam hal ini, tokoh profesor telah mengabaikan tahap religius karena dia kehilangan kontrol akan hati nuraninya dalam memegang teguh keyakinan bahwa tindakan pembunuhan merupakan tindakan yang dilaknat Tuhan.

Salah satu absurditas adalah cerita yang tidak berakhir, tidak ada kata 'tamat', tetapi cerita di dalam naskah tersebut berputar terus sebab penutup cerita adalah pembukaan itu sendiri. Jadi cerita akhir dalam naskah terus berulang kembali pada awal cerita naskah.

Pembantu: (dari balik dinding samping pentas) ......ya,.....sebentar sabar, saya datang.

Pembantu: Selamat siang, Nona.

Murid: Selamat siang, Tuan. Profesor ada di rumah...?

Dialog di atas adalah dialog akhir pada naskah "Pelajaran" dan juga merupakan dialog awal pada naskah tersebut. Dalam hal ini, Ionesco ingin melukiskan bahwa kehidupan manusia seperti roda yang berputar, tidak ada awal dan akhir. Melainkan selalu berputar berulang-ulang, itulah siklus kehidupan. Ionesco juga mengisyaratkan keabsurdan hidup tanpa tujuan yang direpresentasikan para lakon yang tidak menemukan ujung pangkal. Semuanya terulang seperti kejadian sebelumnya.

Ciri lain dalam naskah "Pelajaran" adalah tidak menggunakan nama tokoh melainkan dengan nama profesi yaitu profesor selaku tokoh primer atau utama, murid selaku tokoh sekunder, dan pembantu selaku tokoh tritagonis. Di dalam pendeskripsian tokoh, pengarang tidak memberikan gambaran secara rinci sehingga naskah tersebut menjadi open interpreted bagi calon sutradara yang hendak menggarap naskah drama tersebut.

Tokoh profesor sangat dinamis dan berperan sebagai tokoh yang banyak mengalami keabsurdan dalam naskah, hal ini diawali dengan datangnya seorang murid yang hendak belajar kepadanya. Dalam proses pembelajaran tersebut, tokoh profesor dengan sengaja memanfaatkan keuntungan dominatifnya terhadap muridmuridnya melalui pelajaran bahasa, dan kemudian membunuhnya.

PROFESOR: (kehabisan nafas, dengan suara terputus-putus ) Sundal, ... aku telah melakukannya dengan baik...aku puas...He he aku letih bukan main.... Aku susah bernafas....ah ! (dia kelihatan susah bernafas : dia jatuh untung di situ ada kursi, dia menghapus dahinya, dia dengan terputus-putus mengucapkan sesuatu yang tidak bisa ditangkap artinya. Nafasnya kemudian menjadi wajar kembali....dia bangkit berdiri, dia mengamati pisau di dalam tangannya, lalu melihat kearah gadis itu, setelah itu sikapnya seperti seolah-olah baru bangun tidur)

Setelah membunuh muridnya, profesor tersebut seolah-olah tidak sadar dengan apa yang telah dikerjakannya. Hal ini terlihat pada dialog berikut ini:

PROFESOR: (kebingungan) Apa yang telah kulakukan? Apa yang akan terjadi dengan diriku ? apa yang akan terjadi ? Ah ! Lihat! Lihat! Malapetaka besar ! Nona, Nona berdirilah (dia menggerakgerakkan badannya, pisau masih berada dalam tangannya, dia tidak tahu apa yang mesti diperbuatnya dengan pisau itu) Maaf nona pelajaran telah selesai .... Anda boleh pergi lain kali saja anda membayar...oh! Dia mati....mati....oleh pisau lipatku...dia ma-ti.

Yang kedua adalah tokoh murid. Murid di dalam naskah tersebut digambarkan oleh Ionesco dengan karakter yang disiplin dan sangat menghormati tokoh profesor dalam kegiatan pembelajaran. Hal ini dapat disimak dari dialog di bawah ini:

MURID: (Lincah seperti anak ABG) Ya, Tuan, selamat siang. Seperti Tuan lihat, saya datang tepat waktu. Saya tidak mau datang terlambat, seperti orang kebanyakan.

Profesor: cepatlah. Pergi lekas dari tempat itu. mengganggu saja. 
Pembantu: ya, tuan. saya akan segera pergi. (dia sudah siap untuk pergi) maafkan tuan, tetapi anda harus berhati-hati. saya nasihatkan agar anda berlaku tenang.

Profesor: kau gila, lewa! ayo sana ! kau tidak perlu cemas.

Pembantu: Anda selalu berkata begitu.

Yang ketiga adalah tokoh pembantu, dimana tokoh ini bertugas sebagai penyeimbang di antara tokoh profesor dan murid. Tokoh pembantu ini juga sebagai pengingat sosok profesor yang hendak melakukan rutinitas yang berujung pada perbuatan kriminal, yaitu pembunuhan. Hal ini dapat disimak dari dialog di bawah ini:

Pembantu: tidak, tuan, tidak !... jangan !.. . itu akan berbahaya.

Profesor: lewa, keterlaluan kamu........

Pembantu: Tuan, jangan ilmu pengetahuan bahasa, ilmu pengetahuan bahasa akan menjurus kebinatang buas

Dialog di atas menggambarkan bahwa tokoh pembantu mengingatkan profesor untuk tetap tenang ketika belajar pelajaran berhitung dengan murid. Karena hal ini sudah menjadi rutinitas ketika profesor memulai pelajaran dengan pelajaran berhitung maka dia akan gugup dan akan melanjutkan dengan pelajaran bahasa yang akan berujung kepada perbuatan buas yaitu pembunuhan.

Di samping itu, pertanyaan-pertanyaan yang diajukan oleh tokoh profesor kepada tokoh murid menunjukkan keabsurdan yang jelas, dimana pertanyaan tersebut adalah pertanyaan yang sangat mudah sebenarnya untuk dijawab oleh seorang promopenda yang akan menghadapi ujian doktoralnya. Akan tetapi disitulah letak keabsurdan "Pelajaran", yang memandang hidup tidak masuk akal. Konsep tersebut dihadirkan oleh Ionesco melalui gaya dialog para tokoh seperti yang dapat dicermati di bawah ini:
PROFESOR: Juga tidak, Nona. Tetapi, kalau boleh, dapatlah Nona mengatakan, Paris itu ibukota negeri mana, Nona?

MURID: (Berpikir sejenak).... Paris, ibukota dari Perancis?

PROFESOR: Bagus! Bagus sekali. Rupanya Nona cukup menguasai ilmu bumi.

Selain dialog di atas, terdapat juga beberapa dialog yang mengandung pertanyaan tokoh profesor kepada muridnya :

PROFESOR: Berapa 1+1 ?

\section{MURID}

$1+1=2$

PROFESOR: (HERAN ATAS
PENGETAHUAN MURID
PEREMPUAN ITU) Oh, itu betul kali
Ternyata Anda sudah sangat maju
dengan pelajaran Anda. Anda tidak akan
mendapatkan kesulitan dengan ujian
doktoral umum Anda, Nona. Mari kita
lanjutkan. Berapa $2+1$ ?

Dialog di atas menunjukkan bahwa soal berhitung yang diajukan oleh tokoh profesor pada umumnya sangatlah mudah, apalagi bagi seorang promopenda. Akan tetapi bukan masalah soal yang diajukan oleh tokoh yang hendak disampaikan oleh pengarang, melainkan keabsurdan dan inkonvensionalitas yang disampaikan melalui representasi dialog yang tidak logis. Hal inilah yang menjadi ciri pembeda antara naskah drama konvensional yang sesuai dengan konvensi atau kaidah drama dengan drama absurd yang selalu menyimpang dari drama konvensional. Lebih lanjut berikut ini akan dikutipkan juga dialog antara profesor dengan murid mengenai soal yang tidak logis.

PROFESOR: 4 - 3 ........ Berapa? Ayo berapa? Mudah sekali.

MURID: 4? 
PROFESOR: Bukan, Nona, itu tidak betul.

MURID: 3, kalau begitu.

PROFESOR: Juga bukan, Nona... Maafkan, saya harus mengatakan bahwa itu salah. Maaf.

Kutipan dialog di atas juga menggambarkan absurditas dialog yang tidak logis, terepresentasi melalui dialog profesor kepada muridnya mengenai soal pengurangan yang mudah. Keironisan jawaban tokoh murid adalah simbol dari manusia yang selalu mengedepankan hasyrat dan ego dalam kehidupan. Ilmu hitung adalah ilmu mengenai penjumlahan dan pengurangan. Ini merupakan sebuah analogi dari kehidupan, jika hidup dianalogikan sebagai ilmu hitung, maka dalam berkehidupan, manusia tidak boleh untuk selalu menambah melainkan juga harus mengurangi. Untuk menjelaskan uraian dari soal pengurangan yang mudah tersebut, untuk kesekian kalinya pengarang melukiskan absurditas yang jelas, yakni dengan adanya adegan yang tidak logis. Seperti dapat disimak dari kutipan di bawah ini:

Profesor: lihat, disini ada tiga korek api. Dan disini masih ada lagi, jadi Semuanya ada 4 . lihat baik-baik. Anda punya 4 korek api. Kemudian saya ambil satu. Berapa yang masih tinggal? (DIATAS PENTAS TIDAK TERLIHAT KOREK API MALAH BENDA-BENDA LAIN YANG DIBICARAKAN DISINI JUGA TIDAK ADA. KEMUDIAN PROFESOR ITU BERDIRI, LALU DIA MENULIS DIATAS PAPAN TULIS FIKTIF DENGAN KAPUR TULIS FIKTIF)

Kalimat bercetak tebal di atas adalah adegan yang dilakukan tokoh profesor ketika memberikan penjelasan mengenai soal pengurangan yang diajukan oleh profesor. Terlihat jelas bahwa adegan di atas syarat dengan absurditas yang menunjukkan ketidaklogisan adegan. Hal ini akan sangat nampak sekali ketika naskah drama "Pelajaran" tersebut digarap dan dipentaskan. Hal ini sesuai dengan pernyataan Ionesco dalam Esslin bahwa panggung pementasan memiliki daya magis tersendiri meskipun di luar kerangka rasionalitasnya. Dengan demikian naskah drama absurd mencoba untuk menunjukkan bahwa dunia ini sukar untuk dimengerti (The theatre of absurd shows the world as

an incomprehensible place). Maka hasilnya, pembaca dan penonton akan merasa hidup di dunia yang bahasanya asing sehingga menimbulkan alienasi. Di samping itu Ionesco mempertegas bahwa drama bukanlah sekedar bahasa karena bahasa sendiri dapat dibaca, akan tetapi drama atau teater sejati hanya dapat terwujud dalam pertunjukan (Esslin, 1960). Hal ini menunjukan jelas bahwa naskha drama, khususnya naskha drama absurd, diciptakan oleh pengarang dengan tujuan untuk dipentaskan agar tergambar jelas absurditas yang terkandung dalam naskah drama.

Adegan tokoh profesor yang tidak masuk akal tersebut diulang lagi oleh pengarang dalam naskahnya untuk kesekian kalinya dalam upaya penegasan akan abstraknya kehidupan. Bahkan dalam adegan-adegan berikutnya disertai dengan dialog yang menimbulkan suspense karena adanya ketidakterimaan tokoh murid terhadap profesor yang menjelaskan mengenai soal pengurangan tadi, seperti dapat dilihat pada kutipan di bawah ini:

PROFESOR: Mari kita pindah kesoal lain.... Kita bahasi diri kita dengan angka 1 sampai 5 , untuk mengurangi.. sebentar, nona. Anda akan segera mengerti saya akan menerangkan kepada anda. (MENULIS SEOLAH DI PAPAN TULIS MEMBUAT GARIS DAN HIMPUNAN SAMPAI ANGKA 4) anda lihat?

Tokoh profesor melakukan adegan yang abstrak untuk kesekian kalinya guna menyampaikan absurditas hidup manusia yang terkadang juga terdapat hal-hal yang abstrak dan tidak dapat dipahami.

PROFESOR: (seperti burung kukuk ) Pisau lipat....pisau lipat.

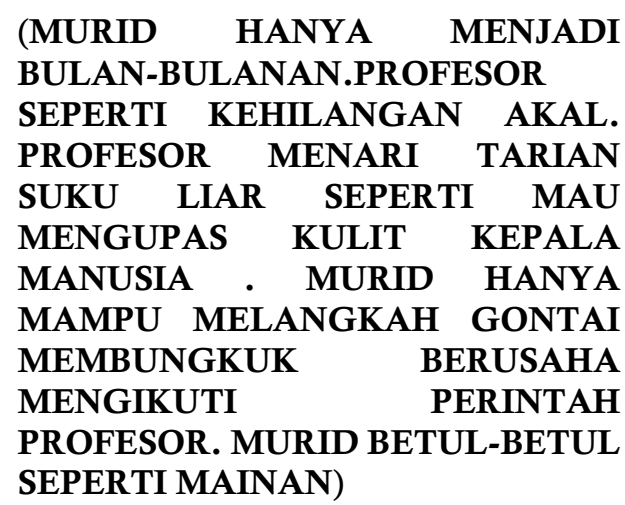


PROFESOR: Tirukan saya, tirukan saya .....pisau lipat....pisau lipat....pisau lipat....

Di bagian klimaks naskah "Pelajaran", pengarang lagi-lagi memunculkan absurditas yang jelas dengan cara menggambarkan tokoh profesor dengan adegan yang tidak logis dan sangat menyimpang dari drama konvensional. Tokoh profesor melakukan tindakan pembunuhan terhadap tokoh murid hanya karena perbedaan pandangan mengenai kehidupan yng direpresentasikan dengan pertanyaan-pertanyaan yang mudah. Tokoh profesor melakukan gerakangerakan yang abstrak seperti menari-nari suku liar dan berkukuk seperti burung yang hendak menerkam mangsanya. Adegan tersebut juga merupakan sebuah bukti atas apa yang telah dinyatakan Ionesco dalam Esslin (1960) bahwa segala tindakan manusia tidak masuk akal, absurd, dan sia-sia.

Adegan, dialog, dan gerak tokoh yang digambarkan oleh pengarang dalam "Pelajaran" merupakan sebuah absurditas yang hendak disampaikan oleh pengarang. Peristiwa-peristiwa yang dilakukan oleh para tokoh menggambarkan kelakuan yang jelas-jelas berada di luar pengalaman rasional. Sehingga menimbulkan ketegangan dan keterasingan pembaca dalam memahami naskah absurd.

Dialog merupakan bagian dari naskah drama yang berupa percakapan antara satu tokoh dengan tokoh yang lain. Dialog adalah bagian yang paling dominan dalam drama. Dialog merupakan salah satu aspek utama yang membedakan drama dengan karya sastra lainnya, puisi dan prosa. Dalam naskah "Pelajaran" dialogdialog yang digunakan berjalan lancar dan penuh dinamika sebab bahasa yang digunakan adalah bahasa formal. Akan tetapi dengan kepiawaiannya penulis, dialog-dialog tersebut tidak mudah ditafsirkan karena mengingat "Pelajaran" adalah naskah absurd.

PROFESOR: Hebat sekali. Anda hebat sekali. Anda luar biasa. Terimalah ucapan selamat saya, Nona. Tak ada gunanya kalau kita teruskan hal ini. Anda pintar sekali dalam menjumlah. Sekarang mari kita mengurangi. Kalau Anda tidak letih, katakanlah 4-3?

MURID: $4-3$ ? ........ 4- 3 ? dikurangi 3 .

PROFESOR: Ya, maksud saya
MURID: Yaitu .............. 7

PROFESOR: Maaf, saya harus menyangkal Anda, 4 dikurangi 3 tidak sama dengan 7. Anda telah mengacaukannya, 4 ditambah 3 adalah 7 , 4 dikurangi 3 tidak sama dengan 7 .... Ini bukan menjumlah melainkan mengurangi.

Dalam kutipan dialog antara tokoh profesor dan murid di atas, menggambarkan bahwa bahasa yang digunakan formal dan mudah untuk ditangkap artinya, akan tetapi pada satu sisi, secara logika kenapa tokoh murid tidak bisa menjawab pertanyaan si profesor tentang pengurangan dalam ilmu hitung. Inilah salah satu absurditas yang ada dalam "Pelajaran" yang kadang-kadang tidak dapat diterima logika.

\section{SIMPULAN}

Absurditas dalam "Pelajaran" disuguhkan melalui penyimpangan struktur batin naskah drama dalam tradisi drama konvensional. Kesemrawutan alur, kesenduan metafisik yang lahir dari mimpi-mimpi buruk kehidupan yang kerap kali bernada pesimistik dan nihilisme, ketidakbernalaran cerita, ketidaklogisan aktor, serta dialog yang tidak ada juntrungnya merupakan gagasan-gagasan absurditas yang terlukis jelas di dalam "Pelajaran." Kompetensi interpretasi naskah absurd menuntut kepekaan intelektual dan pengalaman terhadap penghayatan kehidupan batiniah agar segala absurditas tampak nyata. ketika pembaca naskah absurd merasa terasing, terisolasi sehingga melahirkan pemberontakan dalam diri, disitulah sejatinya letak keberhasilan suatu pembacaan dan perenungan absurdisme.

\section{DAFTAR PUSTAKA}

Christomy. Tomy. (2004). Semiotika Budaya. Pusat Penelitian Kemasyarakatan dan Budaya Direktorat Riset dan Pengabdian Masyarakat Universitas Indonesia.

Esslin, Martin. (2008). Teater Absurd. Mojokerto: Pustaka Banyumili.

4 Handayani, Sri. (2008). Kritik Sosial dalam Kumpulan Puisi Refrein di sudut DAM karya D. Zawawi 
Eka Yusriansyah / Jurnal Sastra Indonesia 8 (2) (2019)

Imron. Skripsi. Universitas Muhammadiyah Surakarta.

Hassan, Fuad. (1976). Berkenalan Dengan Eksistensialisme. Jakarta: Pustaka Jaya.

Jorgensen, M.W., L.J. Philips. (2007). Analisis Wacana: Teori dan Metode. Yogyakarta: Pustaka Pelajar.

Kaelan. (2009). Filsafat Bahasa Semiotika dan Hermeneutika. Yogyakarta: Penerbit Paradigma Karmini, Ni Nyoman. (2011). Teori Pengkajian Prosa Fiksi dan Drama. Denpasar: Pustaka Larasan.

Nafas, Michael. (2014). Pertunjukan, Seni Panggung Kematian Ionesco dalam (http://jogjareview.net/seni/panggungkematian-ionesco//) diakses pada hari Minggu, 16 November 2014.

Riffaterre, Michael. (1978). Semiotics of Poetry. London: Indiana of University Press.

Sudjiman, Panuti. (1986). Kamus Istilah Sastra. Jakarta: Gramedia. 